\title{
THE CHANGES IN THE SERUM PROTEINS IN PATIENTS WITH EXPERIMENTALLY INDUCED INFECTIOUS HEPATITIS ${ }^{1}$
}

\author{
By W. PAUL HAVENS, JR., AND THOMAS L. WILLIAMS \\ (From The Jefferson Medical College, Philadelphia, Pa.)
}

(Received for publication January 2, 1948)

The alterations in the partition of the serum proteins of patients with infectious hepatitis have been described as an early decrease in serum albumin with an increase in serum globulins (1-4). Both alpha and beta globulins are augmented but the greatest increase is in the gamma globulin fraction. It has been pointed out that qualitatively similar changes occur in several other acute infectious diseases, and it has been suggested that these alterations are non-specific in character (5). Such changes have been described as occurring in malaria (6), pneumonia (7), scarlet fever (5), rheumatic fever $(5)$, typhus $(8,9)$, and infectious mononucleosis (10).

Many of the early studies were made by the Howe method of salt fractionation (11), although several more recent descriptions of electrophoretic analyses have supplemented these studies and have defined more accurately the changes in the partition of serum proteins. The discrepancy between the results of analysis of pathologic sera by electrophoresis and the Howe method of salt fractionation has made the former the method of choice, although it is not applicable to clinical use (12).

Recently, another method of salt fractionation of serum proteins by differential precipitation with 19.6 per cent and 26.8 per cent sodium sulfate has been described (13). Excellent correlation of the results of this method and electrophoretic analysis of both normal and pathologic sera has been reported $(14,15)$.

During the past three years, experiments conducted by the Neurotropic Virus Disease Commission on the transmission of infectious hepatitis to human volunteers have made it possible to study the pattern of change in the serum proteins of such patients throughout the course of disease. It is the purpose of this paper to report the al-

1 This investigation was conducted in part with the aid of the Commission on Virus and Rickettsial Diseases, Army Epidemiological Board, Office of the Surgeon General, U. S. Army, Washington, D. C. terations in serum proteins, as determined by a method of differential precipitation, in 29 patients during the course of experimentally induced infectious hepatitis.

\section{METHODS AND MATERIALS}

Subjects. The subjects were previously healthy, male human volunteers, ranging in age from 19 to 29 years. These men contracted infectious hepatitis experimentally after inoculation or ingestion of material known to contain hepatitis virus. The diagnosis of infectious hepatitis was made on the basis of characteristic symptoms and signs accompanied by fever and consistent deflection of the bromsulfalein dye ${ }^{2}$ retention (16) and cephalincholesterol flocculation (17) tests. All patients in this report had clinical jaundice. Two of the patients included in this series had bacteremia with Sal. cholera suis superimposed on their experimentally induced infectious hepatitis (18). The changes in serum proteins in these two patients were qualitatively similar to the rest of the group, although one of these men had more extreme deflections associated with his more severe illness.

Virus. The strain of virus used in this laboratory was originally obtained from the stool of a U. S. Army soldier who contracted epidemic infectious hepatitis in Sicily in 1943 (19). It has been through four passages in human volunteers to date. This agent is filtrable through a Seitz EK filter, and withstands heating to $56^{\circ} \mathrm{C}$. for at least 30 minutes (20). It has produced the disease in 29 out of 40 human volunteers after parenteral or oral inoculation, with incubation periods ranging from 15 to 34 days.

Laboratory observations. 235 determinations of total serum protein, serum albumin, euglobulin and pseudoglobulin were made on the 29 human volunteers. Total nitrogen was determined, by the micro-Kjeldahl technique, in the whole serum and on aliquots of the various fractions following differential precipitation. All analyses were performed in duplicate. The non-protein nitrogen was determined by the method of Bock and Benedict (21), using a Pregl steam-distillation apparatus. Fractionation of serum proteins was performed by precipitation with 26.8 per cent and 19.6 per cent sodium sulfate, according to the method of Majoor (13) modified by Milne (14). The sera used had been stored at dry

\footnotetext{
2 Retention of 10 per cent of dye 30 minutes after the intravenous injection of $5 \mathrm{mgm}$. of bromsulfalein per $\mathbf{~ k g m}$. of body weight was considered the maximum normal.
} 
ice-box temperature for periods ranging from one to two and a half years. The range and average determinations of the various components of the serum proteins of these 29 human volunteers were compiled before experimental inoculation. The results appear in Table $I$, and are used as averages against which the deflections of individual responses during the course of disease are plotted in various charts.

In these experiments, the total serum proteins and their components were determined once every ten days for one month after the onset of disease; at least once every two
TABLE I

Range and average amounts of components of serum protein in 29 healthy human volunteers before experimental inoculation with virus of infectious hepatitis

Range $\mathrm{gm} . / 100 \mathrm{ml}$.

Total protein

$5.60-8.36$

Albumin

$3.58-4.99$

2.00-3.57

Euglobulin

$1.04-2.40$

$0.60-1.17$

Average

Pseudoglobulin
6.93

4.35

2.57

1.75

0.81

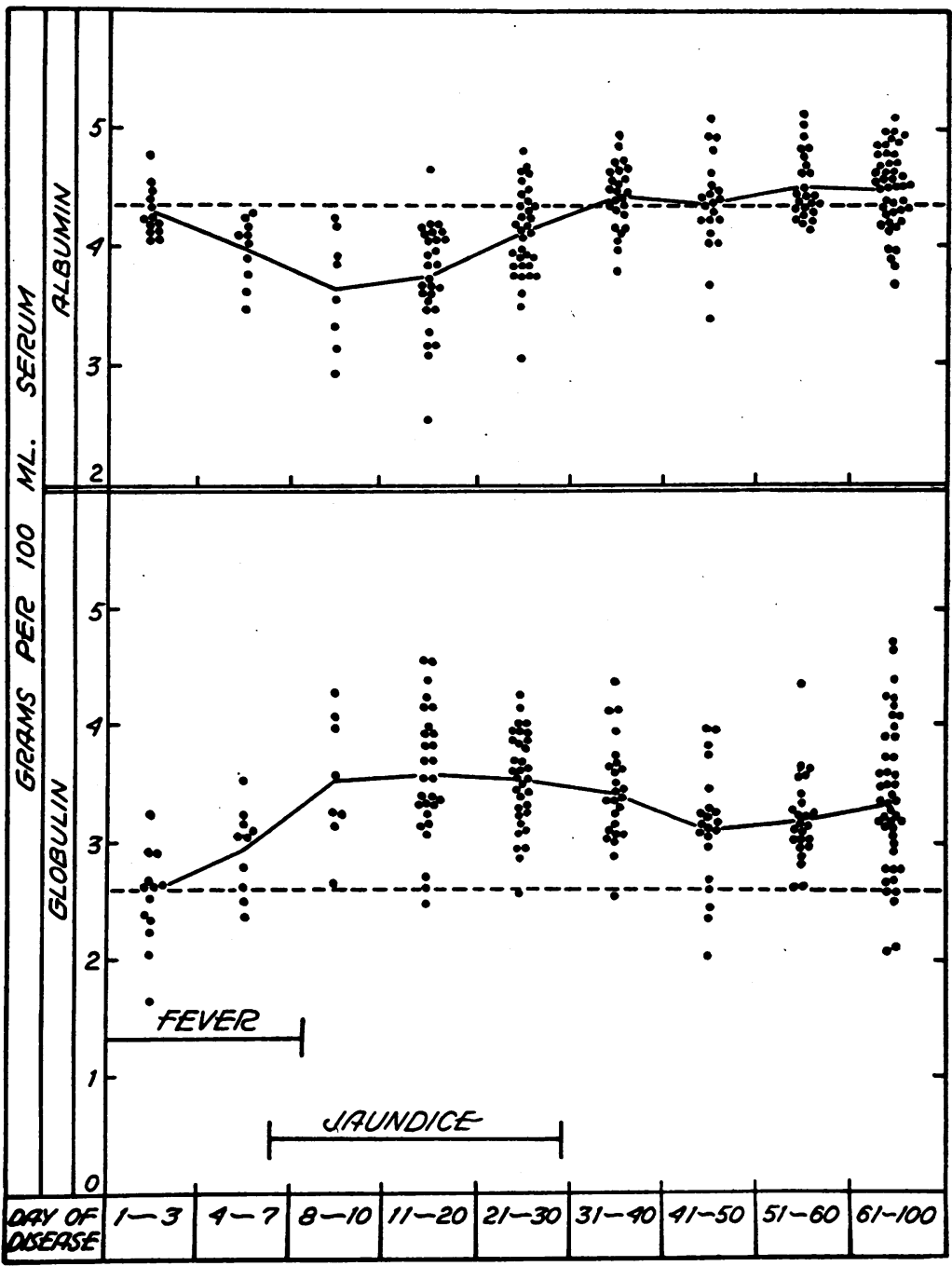

Fig. 1. Determinations of Albumin and Globulin in the Serum of 29 Patients with Experimentally Induced Infectious Hepatitis

Black dots indicate the individual determinations which are expressed as an average by the unbroken lines. The duration of fever and jaundice and the appearance time of jaundice represent the averaged experiences of the 29 patients. The horizontal (broken) lines indicate the average of the preinoculation determinations in the 29 patients. 


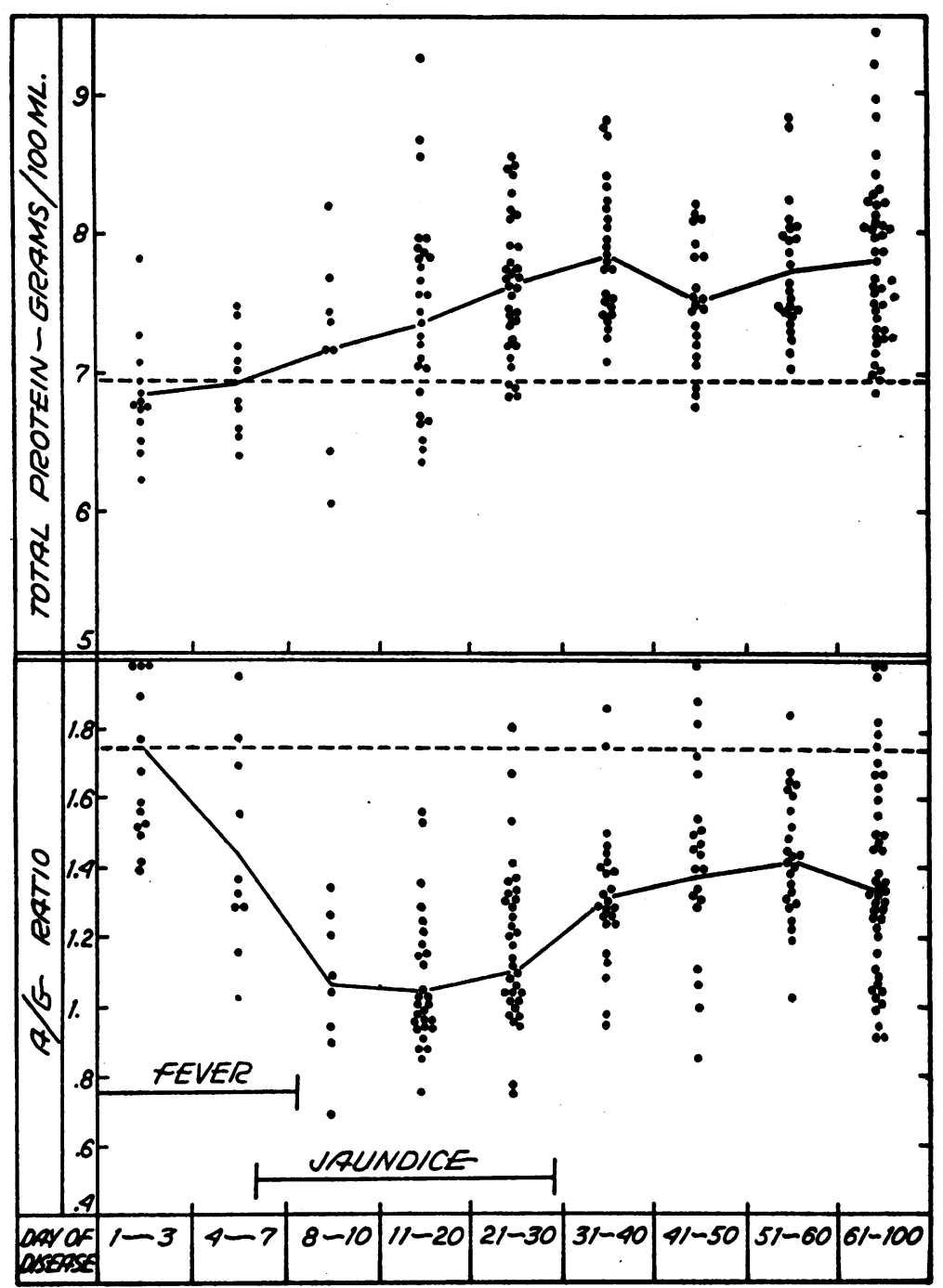

Fig. 2. Total Serum Protein and Albumin/Globulin Ratios in 29 Patients with Experimentally Induced Infectious Hepatitis

Black dots indicate the individual determinations which are expressed as an average by the unbroken lines. The duration of fever and jaundice and the appearance time of jaundice represent the averaged experiences of the 29 patients. The horizontal (broken) lines indicate the average of the preinoculation determinations in the 29 patients.

weeks for the second month after the onset; and at least once in the third month.

\section{RESULTS}

When determinations of the total serum proteins and their components were made this frequently, a regular pattern of response in infectious hepatitis was observed. The 29 patients reported here may be almost equally divided into two groups. One group had an acute onset of disease with fever. The other group had an insidious onset with vague abdominal symptoms for periods of two to 11 days before the appearance of fever.

By using the appearance of fever as a fixed point, it is possible to present the alterations occurring in the serum proteins in all 29 patients of this series. When this is done, and the average 
duration of fever and jaundice and the appearance time of jaundice are recorded, it is seen that moderate alterations in the serum proteins occur in a certain proportion of patients during the febrile phase before the appearance of jaundice, and that with defervescence and appearance of jaundice at the beginning of the second week almost all patients tested showed considerable deflection from normal (Figure 1).

For purposes of convenience, the results of the determinations of serum proteins and their components are described as occurring in three phases; namely (1) the febrile (pre-icteric) phase, (2) the icteric (post-febrile) phase, and (3) the convalescent (post-icteric) phase.

Febrile (pre-icteric) phase. The duration of fever ranged from four to 14 days, averaging eight days. During the first week after the appearance of fever, there is little or no change in the total proteins, but there is a mild decrease in serum albumin and an increase in serum globulin. These slight changes become more evident after the third day.

Icteric (post-febrile) phase. Clinical jaundice appeared from three to 12 days after the beginning of fever, averaging six days. The duration of jaundice ranged from eight to 31 days, with an average of 20 days. Characteristically, clinical jaundice appears with defervescence at the end of the first week. Early in the second week, there is a sharp decrease in amount of serum albumin accompanied by a proportionally greater increase of serum globulin, to the extent that the total amount of serum protein increases and the albu$\mathrm{min} /$ globulin ratio is reversed (Figure 2). The albumin may diminish to as little as $2.5 \mathrm{gm}$. per $100 \mathrm{ml}$., and the globulin increase to $5.0 \mathrm{gm}$. per $100 \mathrm{ml}$. serum. The increment in globulin consists largely of euglobulin, although the pseudoglobulin increases slightly so that there is considerable alteration of the euglobulin/pseudoglobulin ratio (Figure 3). During the third week of disease, the serum globulin rises still further, accompanied by a slight increase in -serum albumin, so that the total amount of serum protein increases. Through the fourth week, as jaundice wanes, the serum albumin continues to rise, while the serum globulin remains constant. The total protein increases slightly, reflecting the increase in serum albumin. During the third week, the euglobulin continues

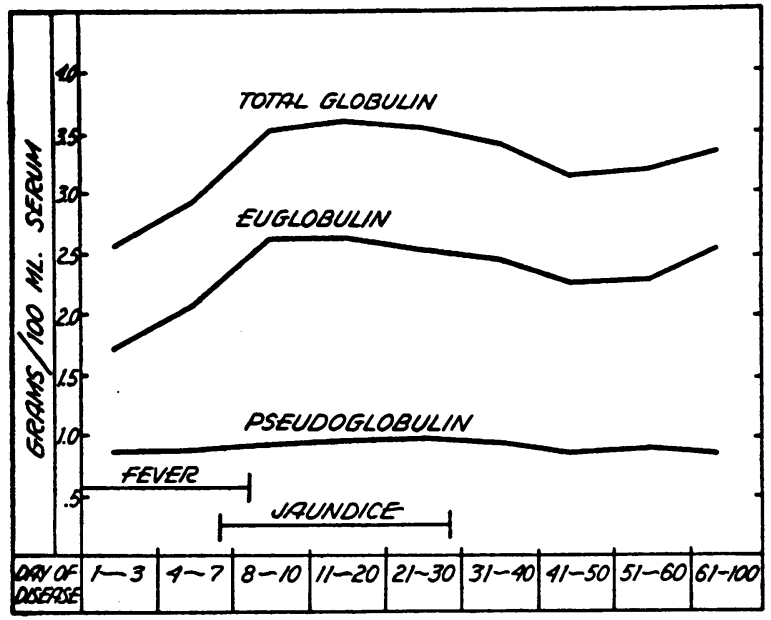

Fig. 3. Averaged Determinations of the Total Globulin, Euglobulin and Pseudoglobulin in the Serum of 29 Patients with Experimentally InDUCEd Infectious Hepatitis

The duration of fever and jaundice and the appearance time of jaundice represent the averaged experiences of the 29 patients.

to increase, declining slightly in the fourth week, while the pseudoglobulin rises gradually during this period, reaching a peak in the fourth week.

Convalescent (post-icteric) phase. During the fifth week of disease, the amount of serum albumin increases to a point slightly above normal, continuing at this level during the next three weeks. The serum globulin slowly declines during this period, becoming normal in an occasional person although without reaching the average normal level for the group. The euglobulin and pseudoglobulin diminish proportionately. From the eighth to the 14th week, the serum albumin continues at just above a normal level with occasional exceptions, and the serum globulin remains somewhat elevated, resulting in a slight increase in total protein during this period, with an albumin/ globulin ratio below normal. The amount of serum albumin was found to be below $4 \mathrm{gm}$. per $100 \mathrm{ml}$. during this period in two patients with relapse, and in one patient with a prolonged convalescence.

\section{DISCUSSION}

The data presented here indicate that a regular pattern of alteration, in the serum proteins occurs during the course of infectious hepatitis, experimentally induced, in human volunteers. This is 


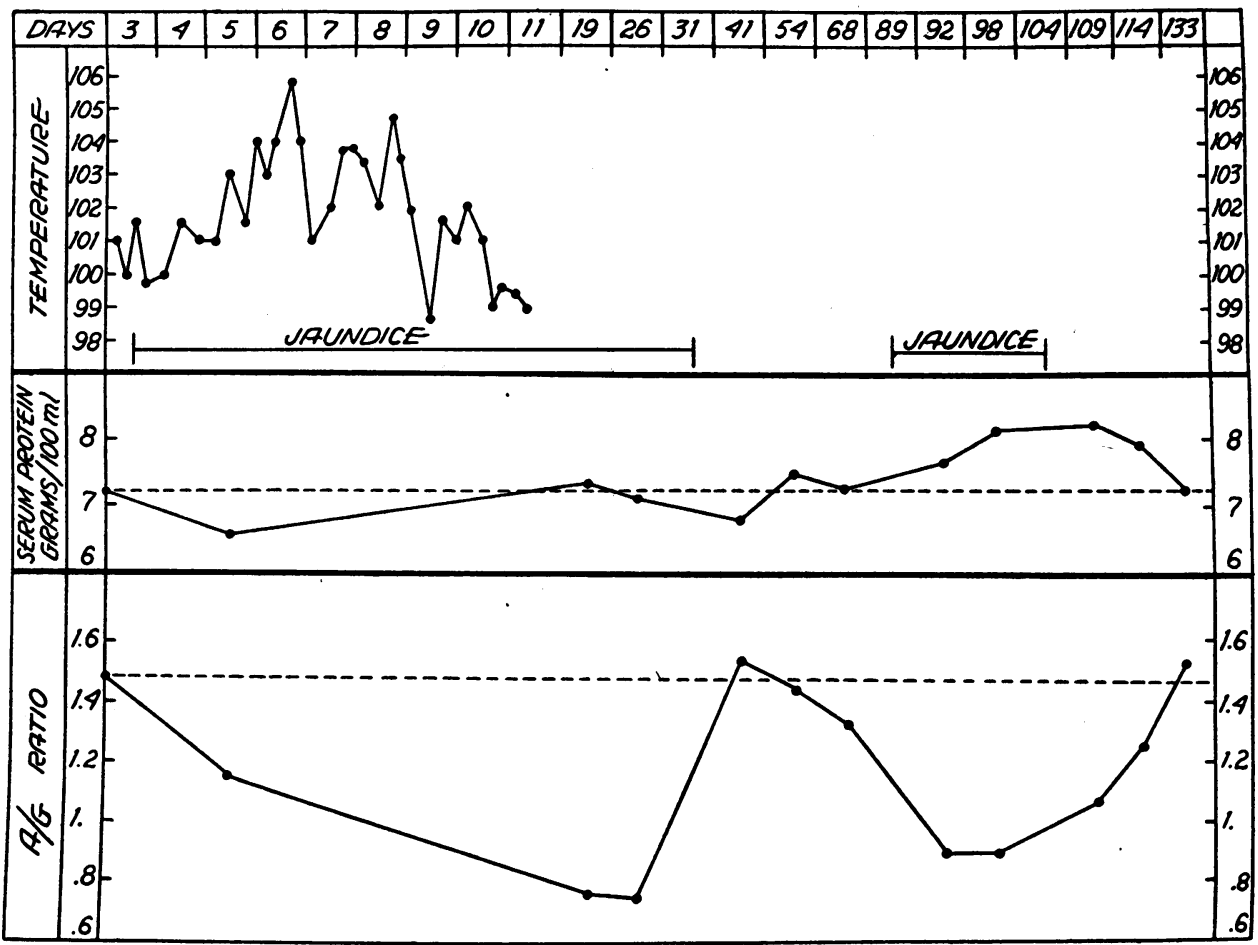

Fig. 4. Course of Disease with Relapse in Patient with Experimentally Induced INFECTIOUS HEPATITIS

Rectal temperatures are recorded. The horizontal (broken) lines indicate the pre-inoculation determinations of total serum protein and albumin/globulin ratio.

in general agreement with the findings of others (1-4) working with both the naturally occurring and experimentally induced disease; it is also similar to the response observed in a number of other acute infectious diseases of diverse etiology.

It is of interest to note that although the serum albumin reaches essentially normal limits by the fifth week after onset, the amount of serum globulins remained elevated well above normal in almost all patients for as long as three and a half months. The exact significance of this finding is undetermined. The increase of globulin is almost wholly in the euglobulin fraction late in convalescence. Since this fraction has been identified with the beta and gamma globulin fractions separated by electrophoresis, the possibility must be considered that a portion of the increment is related to persistence of antibody.

The degree and duration of depression of serum albumin are in direct proportion to the severity of the hepatitis. In two patients who suffered relapse during an apparently normal convales- cence, the characteristic pattern of alteration in serum proteins was repeated at this time, with depression of serum albumin and increase in globulins (Figure 4). Similar findings have been recorded in malaria and rheumatic fever $(5,6)$.

\section{SUMMARY}

1. The results of serial observations of the alterations in serum proteins of patients during $e x$ perimentally induced infectious hepatitis are presented.

2. Although minor changes may occur in the first two or three days of fever, the characteristic response is associated primarily with the period of defervescence at the end of the first week.

3. The pattern of this response is characterized by a sharp decrease in serum albumin with an increase in serum globulins to such a degree that the albumin/globulin ratio is reversed. The increase in globulin is largely in the euglobulin fraction, although the pseudoglobulin increases somewhat. 
4. The serum albumin returns to an essentially normal level in uncomplicated cases during the fifth week, but the serum globulin remains elevated in almost all patients for as long as three and a half months after onset of the disease.

\section{BIBLIOGRAPHY}

1. Gray, S. J., and Barron, E. S. G., The electrophoretic analyses of the serum proteins in diseases of the liver. J. Clin. Invest., 1943, 22, 191.

2. Bjørneboe, M., Studies on the serum proteins in hepatitis. I. The relation between serum albumin and serum globulin. Acta Med. Scandinav., 1946, 123, 393.

3. Martin, N. H., The components of the serum proteins in infective hepatitis and in homologous serum jaundice (an electrophoretic study). Brit. J. Exp. Path., 1946, 27, 363.

4. Neefe, J. R., Results of hepatic tests in chronic hepatitis without jaundice. Gastroenterology, 1946, 7, 1.

5. Dole, V. P., Watson, R. F., and Rothbard, S., Electrophoretic changes in the serum protein patterns of patients with scarlet fever and rheumatic fever. J. Clin. Invest., 1945, 24, 648.

6. Dole, V. P., and Emerson, K., Jr., Electrophoretic changes in the plasma protein patterns of patients with relapsing malaria. J. Clin. Invest., 1945, 24, 644.

7. Moen, J. K., and Reimann, H. A., Plasma protein changes and suspension stability of the blood in lobar pneumonia. J. Clin. Invest., 1933, 12, 589.

8. Tierney, N. A., and Yeomans, A., Metabolic studies on louse-borne typhus. Observations on serum electrolyte pattern, serum protein partition, and nitrogen balance. J. Clin. Invest., 1946, 25, 822.

9. Dole, V. P., Yeomans, A., and Tierney, N. A., Electrophoretic changes in the serum protein pattern of a patient with typhus fever. J. Clin. Invest., 1947, 26, 298.
10. Cohn, C., and Lidman, B. L., Hepatitis without jaundice in infectious mononucleosis. J. Clin. Invest., 1946, 25, 145.

11. Howe, P. E., The use of sodium sulfate as the globulin precipitant in the determination of the proteins in blood. J. Biol. Chem., 1921, 49, 93.

12. Dole, V. P., The electrophoretic pattern of normal plasma. J. Clin. Invest., 1944, 23, 708.

13. Majoor, C. L. H., The possibility of detecting individual proteins in blood serum by differentiation of solubility curves in concentrated sodium sulfate solutions. Yale J. Biol. \& Med., 1946, 18, 419.

14. Milne, J., Serum protein fractionation: a comparison of sodium sulfate precipitation and electrophoresis. J. Biol. Chem., 1947, 169, 595.

15. Majoor, C. L. H., The possibility of detecting individual proteins in blood serum by differentiation of solubility curves in concentrated sodium sulfate solutions. II. Comparison of solubility curves with results of electrophoresis experiments. J. Biol. Chem., 1947, 169, 583.

16. Rosenthal, S. M., and White, E. C., Clinical application of the bromsulphalein test for hepatic function. J. A. M. A., 1925, 84, 1112.

17. Hanger, F. M., Serological differentiation of obstructive from hepatogenous jaundice by flocculation of cephalin-cholesterol emulsions. J. Clin. Invest., 1939, 18, 261.

18. Havens, W. P., Jr., and Wenner, H. A., Infectious hepatitis complicated by secondary invasion with Salmonella. J. Clin. Invest., 1946, 25, 45.

19. Havens, W. P., Jr., Ward, R., Drill, V. A., and Paul, J. R., Experimental production of hepatitis by feeding icterogenic materials. Proc. Soc. Exper. Biol. \& Med., 1944, 57, 206.

20. Havens, W. P., Jr., Properties of the etiologic agent of infectious hepatitis. Proc. Soc. Exper. Biol. \& Med., 1945, 58, 203.

21. Bock, J. C., and Benedict, S. R., An examination of the Folin-Farmer method for the colorimetric estimation of nitrogen. J. Biol. Chem., 1915, 20, 47. 